\title{
THE EFFECT OF HERBICIDE USE ON THE OCCURRENCE OF ENTOMOPATHOGENIC FUNGI IN THE SOIL OF BLACKCURRANT PLANTATIONS
}

\author{
TKACZUK, C. ${ }^{*}$ - MAJCHROWSKA-SAFARYAN, A. \\ Department of Plant Protection and Breeding, Faculty of Natural Sciences, Siedlce University \\ of Natural Sciences and Humanities, B. Prusa 14, 08-110 Siedlce, Poland \\ *Corresponding author \\ e-mail: cezary.tkaczuk@uph.edu.pl \\ (Received $26^{\text {th }}$ Nov 2018; accepted $4^{\text {th }}$ Feb 2019)
}

\begin{abstract}
The aim of the paper was to present species composition and density of colony-forming units of entomopathogenic fungi (EPF) in the soil sampled from the herbicide fallow and sward strips of four blackcurrant (Ribes nigrum L.) fields in Poland. Samples collected in spring and autumn were used as study material. The fungi were isolated with the method of scattering diluted soil onto the selective medium. In order to protect the plants against pests, conventional plant protection was applied to all fields. In the soil taken from the blackcurrant fields three species of entomopathogenic fungi were found: Beauveria bassiana s.l. (Bals.-Criv.) Vuill., Isaria fumosorosea (Wize) and Metarhizium anisopliae s.l. (Metschn.) Sorokin. Both in spring and autumn isolated fungi produced more colony-forming units (CFU) in soil collected from the sward strips than from the herbicide fallow of the blackcurrant fields. In spring B. bassiana s.l. and M. anisopliae s.l. produced more CFU in the soil under sward than in the herbicide strip with intense chemical protection. In the case of I. fumosorosea in spring there was a tendency for CFU to be more numerous in the soil of the herbicide fallow.
\end{abstract}

Keywords: herbicide fallow, colony forming units, Beauveria bassiana, Isaria fumosorosea, Metarhizium anisopliae

\section{Introduction}

For many years Poland has been a leader in the production of blackcurrant fruit, which is an effect of a favourable economic climate and well developed fruit processing industry (Piotrowski et al., 2016). Chemical protection of blackcurrants is based primarily on a large number of chemical treatments, also used to maintain herbicide fallow under bushes and grass between rows of currants. Blackcurrants are perennial plants, which contributes to an increased possibility of pesticide accumulation and results in their residues in the soil. Within the framework of integrated pest management programme, it is recommended to limit significant amounts of chemicals, replacing them with agricultural and biological methods.

Constituting a large group of microorganisms colonizing the soil habitat, EPF have an ability to infect insects, and their development leads to the disruption of physiological processes in the host and to its death in the end (Zimmermann, 2007; Tkaczuk, 2008; Augustyniak-Kram et al., 2013). The anamorphic hypocrealean fungal genera Beauveria, Metarhizium, and Isaria are ubiquitous components of the soil microbiota in temperate regions including agroecosystems, undisturbed/natural landscapes and forests (Chandler et al., 1997; Klingen et al., 2002; Keller et al., 2003). Their basic advantage is the potential to reduce pest populations that infest agricultural and horticultural crops, fruit trees, as well as plants grown under cover (Vänninen et al., 2000; Zimmermann, 2007; Ropek et al., 2014). EPF are the basis for the production of 
bioinsecticides used increasingly in biological plant protection against pests (Faria and Wright, 2007; Zimmerman, 2007). Occurrence and biological activity of EPF are dependent on many factors affecting processes in the soil environment, like: type of soil, air temperature, its humidity, time of year, but also on the availability of hosts and methods of agricultural treatment (Vänninen et al., 2000; Krysa et al., 2012; Tkaczuk et al., 2014). Reports by many authors (Vänninen and Hokkanen, 1988; Miętkiewski et al., 1997; Tkaczuk, 2008; Tkaczuk et. al., 2012; Pelizza et al., 2015; Fiedler and Sosnowska, 2017) indicate that chemical substances in plant protection products can affect EPF and their natural occurrence, species composition, sporulation, colony growth, and infectiousness potential. With a wide range of pesticides used in chemical plant protection, fungicides and herbicides have the most negative effect on the population of fungi and their impact largely depends on the amount of the active substance and on the species of fungus (Andalo et al., 2004; Tkaczuk et al., 2012).

The purpose of this paper is to determine the species composition and density of colony-forming units (CFU) of EPF in soils taken from the grass strip and herbicide fallow of four blackcurrant fields.

\section{Materials and methods}

\section{Soil sampling}

Soil collected in 2012 in two periods (spring and autumn) from four blackcurrant fields located in two localities in Poland: Łuzki (Łosice County) and Żabokliki Kolonia (Siedlce County) was used as research material. Conventional plant protection against pests was used in the fields. Soil samples were taken from two habitats, i.e. from the herbicide fallow under blackcurrant bushes and from the sward between the rows. From 15-20 randomly selected points, soil material was sampled at a depth of $15-20 \mathrm{~cm}$ using a metal soil stick. Characteristics of the studied plantations are shown in Table 1.

Table 1. Characteristics of the blackcurrant plantations

\begin{tabular}{c|c|c|c|c}
\hline Plantation/variety & Locality & $\begin{array}{c}\text { Area of plantations } \\
\text { (ha) }\end{array}$ & $\begin{array}{c}\text { Age of plantation } \\
\text { years }\end{array}$ & Herbicides used \\
\hline I - Tisel & Luzki & 3 & 3 & $\begin{array}{c}\text { Glyphosate }+ \\
\text { MCPA } \\
\text { II - Ben Lomond }\end{array}$ \\
III - Ores & Zlabokliki Kolonia & 1 & 3 & $\begin{array}{c}\text { Glyphosate + } \\
\text { MCPA } \\
\text { Glyphosate }+ \\
\text { MCPA } \\
\text { IV - Ruben }\end{array}$ \\
\hline
\end{tabular}

Soil samples were co-mingled into plastic bags and held at $4{ }^{\circ} \mathrm{C}$. The soil samples were sieved with $3 \mathrm{~mm}$ mesh to separate debris, such as roots and pebbles, and then dried to a moisture content of approximately $25-30 \%$. This is the optimal moisture content for fungal growth and is limiting for the development of entomopathogenic nematodes (Inglis et al., 2012). 


\section{Fungal isolation}

To assess the density of EPF in tested soils, the number of colony forming units (CFU) per gram of dry soil were determined using a selective medium, developed by Strasser et al. (1996). Two grams of soil from each site were added to $18 \mathrm{ml}$ of distilled water with addition of $0.05 \mathrm{ml}$ of Triton X-100. Two serial dilutions were made (1:100 and 1:1000) per sample with a solution of autoclaved $0.10 \%$ Tween 80 surfactant, and four replicates of both dilutions were spread on separate $9 \mathrm{~cm}$ Petri dishes The solution was agitated for 35 seconds before $0.1 \mathrm{ml}$ was applied to media using a sterile pipette. A sterile glass spatula was used to evenly spread the solution on media plates. The selective media consisted of: $20 \mathrm{~g}$ of glucose, $18 \mathrm{~g}$ of agar, $10 \mathrm{~g}$ of peptone, and the selective components: $0.6 \mathrm{~g}$ of streptomycin sulfate, $0.005 \mathrm{~g}$ of chlortetracycline, $0.05 \mathrm{~g}$ of cycloheximide and $0.1 \mathrm{~g}$ of dodine dissolved into $1 \mathrm{~L}$ of distilled deionized water. The supplements streptomycin sulfate, chlortetracycline, cycloheximide, and dodine were added after the media cooled to approximately $30{ }^{\circ} \mathrm{C}$ to avoid degradation. These selective supplements inhibit the growth of saprophytic bacteria and fungi and favour the growth of EPF. Four replicates per sample were prepared and incubated at $22{ }^{\circ} \mathrm{C}$ and after 8-10 days colonies of each fungus species were counted.

EPF were identified on the basis of morphological characteristics, using standard identification keys (Humber, 2012; Inglis et al., 2012). Given that only morphological methods were applied during the identification of fungi, the species Beauveria bassiana and Metarhizium anisopliae were defined sensu lato, because, as demonstrated by the latest phylogenetic studies based on DNA sequence (Bishoff et al., 2006, 2009; Rehner et al., 2011), there are numerous fungus species, both within the genus of Beauveria and Metarhizium, which are impossible to distinguish from each other without the application of molecular methods. The experiment was replicated three times for each soil sample. The findings were presented as the number of colony-forming units (CFU) of each species of EPF in $1 \mathrm{~g}$ of dry soil.

\section{Data analyses}

Since the main aim of the study was to show differences in the occurrence of CFU of particular fungal species between the investigated habitats (sward and herbicide fallow) of each of the four plantations, regardless of the season and location, therefore data on density of EPF CFUs in the field survey were analysed using a 1-way analysis of variance (ANOVA) and means were separated using Tukey's honest significant difference (HSD) test. Values of $\mathrm{P}<0.05$ were considered statistically significant.

\section{Results and discussion}

The main habitat of EPF is soil biomass, of which they constitute an essential part (Ritz and Young, 2004). Their occurrence as well as quantity is affected by a number of biotic and abiotic factors, and also by a wide range of agronomic treatments. The widespread use of pesticides destroying pests in plantations of soft fruit plants is the primary way to reduce their numbers and has a direct impact on the population of EPF in the soil.

This experiment studying the density of colony-forming units (CFU) of EPF in soil sampled from four fields of blackcurrants in two locations in spring and the autumn showed the existence of three species: Beauveria bassiana s.l., Isaria fumosorosea, and 
Metarhizium anisopliae s.1. (Tables 2 and 3). Density of colony-forming units (CFU) of each species was varied depending on the time of year and on the habitat from which the soil was sampled.

Table 2. The density of colony forming units of entomopathogenic fungi $\left(\mathrm{CFU} \times 10^{3} \mathrm{~g}^{-1}\right)$ in soil from blackcurrant plantations in spring

\begin{tabular}{c|c|c|c|c|c|c|c|c|c}
\hline \multirow{2}{*}{ Fungal species } & \multicolumn{9}{c}{ Plantation } \\
\cline { 2 - 10 } & \multicolumn{2}{|c|}{ I } & \multicolumn{2}{|c|}{ II } & \multicolumn{2}{c}{ III } & \multicolumn{2}{c}{ IV } \\
\cline { 2 - 10 } & A & B & A & B & A & B & A & B \\
\hline Beauveria bassiana s.1. & 0.0 & 0.0 & $0.2 \mathrm{a}$ & $0.0 \mathrm{a}$ & $15.9 \mathrm{a}$ & $0.7 \mathrm{~b}$ & $0.3 \mathrm{a}$ & $0.2 \mathrm{a}$ \\
Isaria fumosorosea & $0.5 \mathrm{a}$ & $0.8 \mathrm{a}$ & $0.3 \mathrm{a}$ & $9.2 \mathrm{~b}$ & $2.7 \mathrm{a}$ & $2.5 \mathrm{a}$ & 0.0 & 0.0 \\
Metarhizium anisopliae s.1. & $4.7 \mathrm{a}$ & $0.2 \mathrm{~b}$ & $1.0 \mathrm{a}$ & $1.7 \mathrm{a}$ & $4.7 \mathrm{a}$ & $1.7 \mathrm{~b}$ & $0.7 \mathrm{a}$ & $0.2 \mathrm{a}$ \\
\hline
\end{tabular}

A - sward; B - herbicide fallow

I, II - Łuzki; III, IV - Żabokliki Kolonia; a,b - significance calculated for $\alpha<0.05$

In spring time, in soil sampled from the first blackcurrant field in the village of Łuzki (Luzki I), M. anisopliae s.l. constituted the largest share of the fungi. There were more of its colony-forming units in the soil from the sward than from herbicide fallow, respectively, 4.7 and $0.2 \times 10^{3} \mathrm{~g}^{-1}$. Another species present in this location was $I$. fumosorosea, which was more common in the herbicide strip than in the grass strip. In spring in the soil collected in the other blackcurrant field located in the same village a different relationship was found, where I. fumosorosea and M. anisopliae s.l. produced more colony-forming units in the soil of herbicide fallow than in the sward, respectively, 9.2 and $1.7 \times 10^{3} \mathrm{~g}^{-1}$. In Luzki I there was no the presence of the $B$. bassiana s.l. fungus in either of the strips, and in Łuzki II there was a small amount of it in the sward soil. Vänninen and Hokkaken (1988) found that in a field with soft fruit bushes the $B$. bassiana fungus was the most sensitive to herbicides commonly used to keep herbicide fallow. In the soil collected from both blackcurrant fields in Żabokliki, there were significantly more colony-forming units in the grass between the rows of bushes than in the herbicide fallow. The dominant species in the soil of Żabokliki Kolonia III turned out to be B. bassiana s.l., which in the grass alleys produced $15.9 \times$ $10^{3} \mathrm{~g}^{-1}$ colony-forming units (Table 2). Sapieha-Waszkiewicz et al. (2005) by examining the soil taken from blackcurrant and chokeberry fields found a clear domination of the $B$. bassiana fungus, while in the soil taken from an adjacent field there was a greater volume of the M. anisopliae fungus.

When considering all blackcurrant fields with all soil samples collected in spring $B$. bassiana s.l. and $M$. anisopliae s.l. produced significantly more colony-forming units in the soil taken from the sward area than in the soil of herbicide fallow, while in the case of the I. fumosorosea fungus the opposite tendency was reported (Table 2).

In soil samples taken in autumn in the Łuzki I field B. bassiana s.l. and M. anisopliae s.l. occurred to a greater volume in the soil of the fallow strip than in the sward, producing, respectively, 2.3 and $0.7 \times 10^{3} \mathrm{CFU}$ in 1 gram of soil (Table 3). In the soil taken from the herbicide strip, with intense chemical protection, in the other field (Luzki II) there were no colony-forming units of B. bassiana s.l. or I. fumosorosea, while in the sward strip they produced, respectively, 0.5 and $5.0 \times 10^{3} \mathrm{~g}^{-1}$ of them. The results 
demonstrated a negative impact of intensive chemical protection, especially herbicides used under blackcurrant bushes, on the density of colony-forming units of EPF. Kozanecka et al. (1996) reported that long-standing use of herbicides in an orchard in order to keep land fallow contributed significantly to the reduction of soil biological activity. On the other hand insects, plants and microbial populations will interact at the soil-root interface to affect EPF populations. Some EPF like $M$. anisopliae and $B$. bassiana are ubiquitous insect pathogens and possible plant symbionts, as some strains are endophytic or colonize the rhizosphere (St. Leger, 2008; Pava-Ripoll et al., 2011).

Table 3. The density of colony forming units of entomopathogenic fungi $\left(\mathrm{CFU} \times 10^{3} \mathrm{~g}^{-1}\right)$ in soil from blackcurrant plantations in autumn

\begin{tabular}{c|c|c|c|c|c|c|c|c}
\hline \multirow{2}{*}{ Fungal species } & \multicolumn{9}{c}{ Plantation } \\
\cline { 2 - 10 } & \multicolumn{2}{|c|}{ I } & \multicolumn{2}{c}{ II } & \multicolumn{2}{c}{ III } & \multicolumn{2}{c}{ IV } \\
\cline { 2 - 10 } & $\mathrm{A}$ & $\mathrm{B}$ & $\mathrm{A}$ & $\mathrm{B}$ & $\mathrm{A}$ & $\mathrm{B}$ & $\mathrm{A}$ & $\mathrm{B}$ \\
\hline Beauveria bassiana s.1. & $0.2 \mathrm{a}$ & $2.3 \mathrm{~b}$ & $0.5 \mathrm{a}$ & $0.0 \mathrm{a}$ & $0.3 \mathrm{a}$ & $0.0 \mathrm{a}$ & $2.0 \mathrm{a}$ & $0.3 \mathrm{~b}$ \\
Isaria fumosorosea & $4.5 \mathrm{a}$ & $1.0 \mathrm{~b}$ & $5.0 \mathrm{a}$ & $0.0 \mathrm{~b}$ & $0.2 \mathrm{a}$ & $0.5 \mathrm{~b}$ & $0.5 \mathrm{a}$ & $0.0 \mathrm{a}$ \\
Metarhizium anisopliae s.1. & $0.2 \mathrm{a}$ & $0.7 \mathrm{a}$ & $0.0 \mathrm{a}$ & $0.2 \mathrm{a}$ & $1.2 \mathrm{a}$ & $0.0 \mathrm{~b}$ & $0.5 \mathrm{a}$ & $0.5 \mathrm{a}$ \\
\hline
\end{tabular}

Explanations as for Table 2

I. fumosorosea clearly dominated in the soil of the sward in samples from both blackcurrant fields in Łuzki. In autumn in soil samples collected from the field located in Żabokliki Kolonia (III) B. bassiana s.l. and M. anisopliae s.l. were in greater quantities in the soil of the grass strip between the rows of shrubs, and I. fumosorosea produced much more colony-forming units in the soil of the herbicide fallow. In the case of the other field located in the village, B. bassiana s.l. and I. fumosorosea were in greater abundance in the soil collected from the sward, while the M. anisopliae s.l. species produced the same number of colony-forming units in the soil of both types of habitats.

The use of herbicide fallow in the rows of trees or bushes and grass in the inter-rows as a mechanism for maintaining soil in a good condition, creates specific environment for the development of soil microorganisms. Grassy vegetation roots in sward enable the rhizosphere microflora to develop. Under conditions of herbicide fallow, the biological activity of the soil depends primarily on multiannual, cumulative effect of herbicides (Akopyan and Avetisyan, 1990; Ehle and Laermann, 1991).

The main herbicide used on investigated blackcurrant plantations was glyphosate. A few herbicides, including glyphosate, have been shown to be fungistatic despite their use for weed control. Formulations of glyphosate have been shown to be fungicidal to plant pathogens including Fusarium solani (Martius) Sacardo and Phytophthora spp., but not detrimental to species like Pythium spp. (Kassaby, 1985; Kawate et al., 1992). A study by Morjan et al. (2002) investigated the effects of seven glyphosate formulations on EPF mycelial growth in solid media and found that the fungicidal properties of glyphosate formulations varied among fungal species but that $M$. anisopliae was susceptible to all glyphosate formulations. The fungicidal effects of herbicides like glyphosate may not occur under field conditions where the chemical can bind to clay 
particles in most soil types and reduce its bioavailability and movement through the soil substrate (Morjan et al., 2002).

Many authors point out that the way the soil is cultivated is a factor significantly affecting the species composition of EPF. Tkaczuk (2008) showed in his studies that long lasting use of chemical pesticides might cause resistance reactions of some species of EPF. The phenomenon of the formation of fungal strains with increased resistance to pesticides was also observed by Sapieha-Waszkiewicz et al. (2005). Poprawski and Majchrowicz (1995) holds that EPF probably have a specific system detoxing herbicides. According to the authors, it is a proven fact that some colonies of fungi start growing later, only after a few days of contact with a medium containing herbicides. According to Domsch (1972) soil microorganisms, including fungi, create a series of enzymatic reactions that help them in the process of pesticide degradation.

In all soil samples collected in autumn from all blackcurrant fields it was found that I. fumosorosea created on average significantly more colony-forming units in the sward than in the herbicide fallow. Density of colony-forming units of M. anisopliae s.l. was slightly higher in the soil of the grass strips than the herbicide fallow. The occurrence of B. bassiana s.l., both in the herbicide fallow and sward was on average at similar level.

The experiment showed that in the samples taken in spring and as well in autumn from all the fields, EPF produce together on average significantly more colony-forming units in the soil of the sward between rows of blackcurrant bushes, than in the herbicide fallow strips (Fig. 1). These values were lower in autumn than in spring. Hummel et al. (2002) after many years of carrying out field experiments found that pesticide application significantly limited the occurrence of EPF in the soil. This was confirmed by the research of Sapieha-Waszkiewicz et al. (2005), in which G. mellonella larvae in the soil of a blackcurrant field without any chemical protection against pests were infected by EPF to more than double degree compared to intensively protected field.

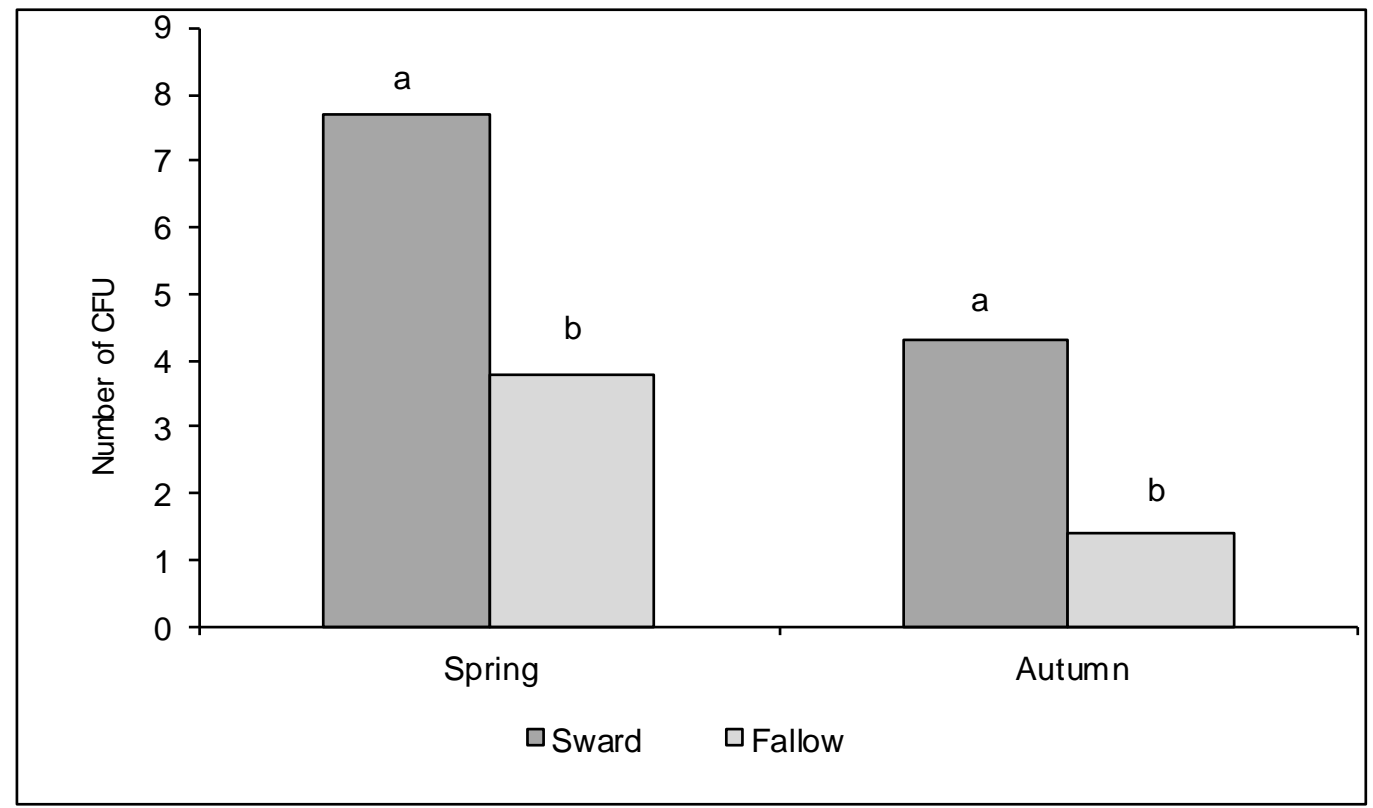

Figure 1. The average number of colony forming units of entomopathogenic fungi in soil (CFU $\times 10^{3} \mathrm{~g}^{-1}$ ) from sward and herbicide fallow of black currant plantations (spring and autumn). Different letters above columns in each habitat indicate significant differences in the values at $\alpha$ $<0.05$ 
According to the Karg and Bałazy (2009) simplified crop rotation, chemical pest and weed control, and periodically repeated tillage treatments, aimed at raising crop yield, eliminate, directly or indirectly, arthropod pathogens together with the parasites and predators as a trophic group with special environmental and nutrient requirements. However, most fungi, including EPF, are characterized by large adaptive capacity to adverse environmental conditions, usually also having high reproductive and migration potential. They may settle back in a habitat during a short period of time, if, as a result of agricultural treatments, they have been eliminated, on condition that the fields or surrounded areas are suitable for their habitat.

\section{Conclusions}

With the method of spreading soil solution on the selective medium of the soil taken from the blackcurrant fields three species of entomopathogenic fungi were identified: $B$. bassiana s.l., I. fumosorosea, and M. anisopliae s.l.. The density of colony-forming units of individual species was varied and dependent on the habitat from which the soil was taken and on the time of year. Both in spring and autumn isolated entomopathogenic fungi produced totally more colony-forming units (CFU) in the soil under grass than in the herbicide strip of blackcurrant fields. When considering all blackcurrant fields, it was found that in spring B. bassiana s.l. and M. anisopliae s.l. produced more $\mathrm{CFU}$ in the soil under sward than in the herbicide strip with intense chemical protection. In the case of I. fumosorosea in spring there was a tendency for $\mathrm{CFU}$ to be more numerous in the soil of the herbicide fallow under the bushes. It meant that this species could be used together with pesticides in integrated protection of blackcurrants against pests. Further studies on pesticide resistance of different isolates of EPF can be performed to search of virulent strains to be applied simultaneously as biopesticides.

Acknowledgements. The research was carried out under research theme No. 360/13/S and were financed from the science grant granted by the Ministry of Science and Higher Education.

\section{REFERENCES}

[1] Akopyan, E. A., Avetisyan, M. Z. H. (1990): Effect of successive application of simazine and dalapon on the biological activity of orchard soils. - Biol Zhur Arm 43: 1025-1027.

[2] Andalo, V., Moino, A., Santa-Cecilia, L. V. S., Souza, G. C. (2004): Compatibility of Beauveria bassiana with chemical pesticides for the control of the coffee root mealybug Dysmicoccus texenis Tinsley (Hemiptera: Pseudococcidae). - Neotropical Entomology 33: 463-467.

[3] Augustyniak-Kram, A., Mazurkiewicz, I., Kram, K. J., Uss, G. (2013): Species structure of insecticide fungi in the soil of the reserve Jata. - Sylwan 157: $572-577$ (in Polish).

[4] Bischoff, J. F., Rehner, S. A., Humber, R. A. (2006): Metarhizium frigidum sp. nov.: a cryptic species of $M$. anisopliae and member of the M. flavoviride complex. - Mycologia 98: 737-745.

[5] Bischoff, J. F., Rehner, S. A., Humber, R. A. (2009): A multilocus phylogeny of the Metarhizium anisopliae lineage. - Mycologia 101: 508-528.

[6] Chandler, D., Hay, D., Reid, A. P. (1997): Sampling and occurrence of enthomopathogenic fungi and nematodes in UK soils. - Applied Soil Ecology 5: 133-140. 
[7] Domsch, K. H. (1972): Interactions of soil microbes and pesticides. - Symposia Biologica Hungarica 337-347.

[8] Ehle, H., Laermann, H. T. (1991): Testing the effects of pesticides on activities of the soil microflora during the authorization procedure. - Nachrichtenblatt des Deutschen Pflanzenschutz Zolinster 43: 116-118.

[9] Faria, M. R., Wright, S. P. (2007): Mycoinsecticides and mycoacaricides: a comprehensive list with worldwide coverage and international classification of formulation types. - Biological Control 43: 237-256.

[10] Fiedler, Ż., Sosnowska, D. (2017): Side effects of fungicides and insecticides on entomopathogenic fungi in vitro. - Journal of Plant Protection Research 57(4): 355-360.

[11] Humber, A. R. (2012): Identification of Entomopathogenic Fungi. Chapter VI. - In: Lacey, L. A. (ed.) Manual of Techniques in Invertebrate Pathology. Academic Press, London.

[12] Hummel, R. L., Walgenbach, J. F., Barbercheck, M. E., Kennedy, G. G., Hoyt, G. D., Arellano, C. (2002): Effects of production practices on soil-borne entomopathogens in western North Karolina vegetable systems. - Environmental Entomology 31: 84-91.

[13] Inglis, G. D., Enkerli, J., Goettel, M. S. (2012): Laboratory techniques used for entomopathogenic fungi: Hypocreales. Chapter VII. - In: Lacey, L. A. (ed.) Manual of techniques in invertebrate pathology. London Academic Press, London.

[14] Karg, J., Bałazy, S. (2009): Effect of landscape structure on the occurrence of agrophagous pests and their antagonists. - Progress in Plant Protection 49: 1015-1034 (in Polish).

[15] Kassaby, F. Y. (1985): Interaction of four herbicides with Phytophthora cinnamomi. Australasian Plant Pathology 14: 21-22.

[16] Kawate, M. K., Kawate, S. C., Ogg, Jr A. G., Kraft, J. M. (1992): Response of Fusarium solani f. sp. pisi and Pythium ultimum to glyphosate. - Weed Science 40: 497-502.

[17] Keller, S., Kessler, P., Schweizer, C. (2003): Distribution of insect pathogenic soil fungi in Switzerland with special reference to Beauveria brongniartii and Metarhizium anisopliae. - BioContro 148: 307-319.

[18] Klingen, I., Meadow, R., Aandal, T. (2002): Mortality of Delia floralis, Galleria mellonella and Mamestra brassicae treated with insect pathogenic hyphomycetous fungi. - Journal Applied Entomology 126: 231-237.

[19] Kozanecka, T., Rokosz-Burlaga, H., Russel, S. (1996): Effect of apple orchard soil management system, liming and nitrogen fertilization in biological activity. - Roczniki Gleboznawcze 47: 75-83 (in Polish).

[20] Krysa, A., Ropek, D., Kuźniar, T. (2012): The occurrence of entomopathogenic fungi depending on season in selected organic farm. - Journal of Research and Applications in Agricultural Engineering 57: 226-230.

[21] Miętkiewski, R., Pell, J. K., Clark, S. J. (1997): Influence of pesticides use on the natural occurrence of entomopathogenic fungi in arable soils in the UK. Field and laboratory comparisons. - Biocontrol Science and Technology 7: 565-575.

[22] Morjan, W. E., Pedigo, L. P., Lewis, L. C. (2002): Fungicidal effects of glyphosate and glyphosate formulations on four species of entomopathogenic fungi. - Environmental Entomology 31: 1206-1212.

[23] Pava-Ripoll, M., Angelini, C., Fang, W., Wang, S., Posada, F. J., St Leger, R. (2011): The rhizosphere-competent entomopathogen Metarhizium anisopliae expresses a specific subset of genes in plant root exudate. - Microbiology 157: 47-55.

[24] Pelizza, S. A., Scorsetti, A. C., Russo, M. L., Sy. V., Pacheco-Marino, S. G. (2015): Use of entomopathogenic fungi combined with biorational insecticides to control Dichroplus maculipennis (Orthoptera: Acrididae: Melanoplinae) under semi-field conditions. Biocontrol Science and Technology 25: 1241-1253.

[25] Piotrowski, W., Łabanowska, B. H., Galińska, A., Curthbertson, A. G. F. (2016): Migration monitoring of blackcurrant gall mite (Cecidophyopsis ribis) Westw. from buds 
to leaves on several blackcurrant (Ribes nigrum L.) cultivars. - Journal of Horticultural Research 24(2): 61-68.

[26] Poprawski, T. J., Majchrowicz, I. (1995): Effects of herbicides on "in vitro" vegetative growth and sporulation of entomopathogenic fungi. - Crop Protection 14: 81-87.

[27] Rehner, S. A., Minnis, A., Sung, G., Lnangsaard, J. J., Devotto, L., Humber, R. A. (2011): Phylogeny and systematics of the anamorphic, entomopathogenic genus Beauveria. - Mycologia 103: 1055-1073.

[28] Ritz, K., Young, I. M. (2004): Interactions between soil structure and fungi. - Mycologist 18: 52-59.

[29] Ropek, D., Krysa, A., Rola, A., Frączek, K. (2014): Antagonistic effect of Trichoderma viride on entomopathogenic fungi Beauveria bassiana, Isaria fumosorosea and Metarhizium anisopliae in vitro. - Polish Journal of Agronomy 16: 57-63 (in Polish).

[30] Sapieha-Waszkiewicz, A., Marjańska-Cichoń, B., Piwowarczyk, Z. (2005): The occurrence of entomopatogenic fungi in soil from the plantations of black currant and aronia. - Electronic Journal of Polish Agricultural Universities 8: 1-8.

[31] St. Leger, R. J. (2008): Studies on adaptations of Metarhizium anisopliae to life in the soil. - Journal of Invertebrate Pathology 98: 271-276.

[32] Strasser, H., Forrer, A., Schinner, F. (1996): Development of Media for the Selective Isolation and Maintenance of Virulence of Beauveria brongniartii. - In: Jackson, T. A., Glare, T. R. (eds.) Microbial Control of Soil Dwelling Pests. AgResearch, Lincoln, New Zeland.

[33] Tkaczuk, C. (2008): Occurrence and infective potential of entomopathigenic fungi in soils of agrocenoses and seminatural habitats in the agricultural landscape. - Scientific Dissertation No. 94. Publisher AP, Siedlce (in Polish).

[34] Tkaczuk, C., Krzyczkowski, T., Głuszczak, B., Król, A. (2012): The influence of selected pesticides on the colony growth end conidial germination of the entomopathogenic fungus Beauveria bassiana (Bals.) Vuill. - Progress in Plant Protection 52: 194-197 (in Polish).

[35] Tkaczuk, C., Król, A., Majchrowska-Safaryan, A., Nicewicz, Ł. (2014): The occurrence of entomopathogenic fungi in soils from fields cultivated in a conventional and organic system. - Journal of Ecological Engineering 15: 137-144.

[36] Vänninen, I., Hokkanen, H. (1988): Effect of pesticides on four species of entomopathogenic fungi in vitro. - Ann Agric Fenn 27: 345-353.

[37] Vänninen, I., Tyni-Juslin, J., Hokkanen, H. M. T. (2000): Presistance of augmented Metarhizium anisopliae and Beauveria bassiana in Finish agricultural soils. - Biocontrol 45: 201-222.

[38] Zimmermann, G. (2007): Review on safety of entomopathogenic fungus Metarhizium anisopliae. - Biocontrol Science and Technology 17: 879-920. 